\title{
Perceptive- Cognitive Functional Learning Model Based on The Self-Management of Students with Autistic Spectrum Disorder: A Comparative Analysis
}

\author{
Manuel Ojea Rúa* and Nuria Diéguez García \\ University of Vigo, Faculty of Education Science, Spain \\ *Corresponding author: Manuel Ojea Rúa, University of Vigo, Faculty of Education Science, Spain. \\ To Cite This Article: Manuel Ojea Rúa, Nuria Diéguez García. Perceptive- Cognitive Functional Learning Model Based on The Self-Management \\ of Students with Autistic Spectrum Disorder: A Comparative Analysis. Am J Biomed Sci \& Res. 2019 - 1(3). AJBSR.MS.ID.000523. \\ DOI: 10.34297/AJBSR.2019.01.000523
}

Received: February 11, 2019 | Published: February 14, 2019

\begin{abstract}
Teaching-learning models applied to students with Autism Spectrum Disorder (ASD) must focus on naturalistic didactic processes to facilitate the self-management of own student through the previous given competences, following local semantic process structure they describe your information processing way. A total of 20 students with ASD have participated in the study, aged between 6 and 14 age years, divided into two groups, an experimental group (EG) consisting of 10 students and a control group (CG) formed by 10 other students. Results found along 3 successive measures over 8 months, performed throughout ANOVA W test of 1 -factor comparative measures, allows to conclude the students who belong to EG significantly improved in aspects related to conceptual coding and in self-management of their own learning, with respect to their CG peers.
\end{abstract}

Keywords: Autism Spectrum Disorder; Cognitive- Perceptive; Naturalistic Learning; Self- Management

\section{Introduction}

Ellis et al. [1] perform a study based on influence analysis of hypotheses theories of Cognitive Central Coherence (CCI), which specifies that information processing of people with Autism Spectrum Disorder (ASD) is of local type and conclude they do not find evidence of these postulates in processing of people with ASD. In this study, they establish a differentiation between local processing, as it's typical of cognitive weakness, contrary to semantic or global processing, but this difference is wrong, since global semantic processing can also be local, observing itself a tendency in processing of children with ASD to local semantic perception, they subdivide into units with meaning, with disabilities to establish a correspondence between conceptual unit with conceptual category and, sometimes, may not be done on the priority or main content, but about irrelevant contents Ojea [2], that corroborate the deficits of global semantic type in people with ASD, which are distinguished by a dominant perception of local semantic way of CCI theory Coderre et al. [3]. Thus, it becomes a basic aim of psychoeducational work for people with ASD ease the global cognitive-perceptual development to achieve semantic processes of growing hierarchy, as well as, the development of categories and their relationships, both between concepts, such as between concepts and categories, therefore principal question is with what methodology we should these cognitive developments and, in this sense, if stronger potential is local semantic processing, it's advisable start from the potential skilss to reach higher possible global development. Research studies related to interventions about behavior improvement ambit are noteworthy. Luxford, Hadwin \& Kovshoff [4] and Mussey \& Dawkins [5] show, i.e., the effectiveness of cognitive treatments to improve behavioral skills of people with ASD, based on a successive intervention progress from previous abilities, using interactive systemic contexts, with participation of all professionals and families as fundamental resources to achieve this proposed aims.

In other studies were researched functional treatments of anxiety processes Moskowitz et al. [6], which, likewise, they start from previous competence development, evaluated from a multiple strategy, as well as, from theoretical base of behaviors as part of the associated global behavior, thoughtful as a multicomponent process, as soon as include different strategies, both individualized positive behavior support skills and cognitive behavioral therapies, 
encouraging, likewise, as they also affirm Clarke, Hill \& Charman [7], the participation of all social factors involved in educational process of children with ASD. These studies move over field of intervention, concluding that exclusively clinical environments must to be replaced for cultural contexts adapted to individual needs, becoming applied programs based on the school and in right context, which allow seeming improvements to happen where exclusively clinical environments don't find them Drmic, Aljunied \& Reaven [8].

Programs development advance, then, towards systemicity of psychological processes as a totality of human behavior, through which, some areas of development become, successively, means to support other areas, but always from child's potential areas. Pan et al. [9] and Ketcheson, Hauck \& Ulrich [10] exhibit the existing relationship, i.e., between motor development within the area of physical education, in relation to executive function, the cognitive processes development properly and socialization processes, respectively, in children with ASD. Also, Tal-Atzili \& Salls [11] investigate and conclude with effectiveness of successive sensory learning, through the development of tactile system in children with ASD, over family support, regarding to improve levels of perceptualcognitive processing of information. Nelson, Paul, Johnston \& Kidder [12] research the area of creative dance to progressively increase social development. In this study, they use main play materials, creative dance activities and complex play sessions with known materials in inclusive contexts to promote global development of people with ASD.

The integrated intervention program, both touch on to the perceptive-cognitive areas, and in context of the intervention itself, characterized by interactivity of all participants, to wit, teachers, families, social and health services and peers, conform to current models, characterized by processes based on natural context Lyons [13]. This model, noted as Pivotal Response Treatment (PRT), it shapes "a naturalistic developmental behavior intervention, is described as a child and family centered model aimed at improving core social- communicative and behavioral siytoms of autism" [13]. PRT is based, above all, in specific interests of children themselves and their previous potential, in order to improve the development of communication, language, play and social relations, through a naturalistic learning- teaching, focused on the different perceptualcognitive areas and family affection, with participation of all factors of natural change, through education, training and empowerment Koegel \& Koegel $[14,15]$. Precisely, basis of this methodology is supported, among others, on principle that people with ASD often tend to focus stimuli from the environment that, sometimes, mayn't be relevant because these people lay to a weak cognitive focus, so that, it's necessary to clearly specify teaching system, applied in environment that's right to it. Therefore, it's essential a process of learning self-initiation, using strategies indicated by children with ASD themselves, because there can't always be a specific teaching program they meets these needs, since, learning to children to selfmanage progressively from the evaluated needs, make up basis of development of the joint attention capacity and attentional selectivity, which improves of skills generalization, self-regulation and independence of children along teaching-learning process. This psychoeducational aim is priority, learning semantic conceptual integration is significantly improved, but, above all, what's more important, development of relationships between this learning and the semantic contents in being in memory is facilitated, to continue in the hierarchy of complexity of the cognitive development.

Didactic methodology must respond to following general characteristics, based to this hypothesis:

i. develop the perceptual-cognitive process, supported by the previously obtained semantic unit,

ii. acquire complex hierarchical semantic levels progressively,

iii. base the practice on needs perceive during learning exchange process,

iv. develop process with participation of family, the teachers and their peers, and

v. systematic evaluate whole process.

\section{Research Aims}

This study aims to analyze the effectiveness of the perceptualcognitive processes integration over curriculum, in relation to curricula that don't integrate these sensory concepts. Within this general aim, research presents following specific aims:

1) Analyze interactive effects between integrated perceptualcognitive hypothesis and conceptual coding.

2) Observe the differences of the effects on experimental group regarding to control group.

3) Study possible differences in relation to participants age interval.

\section{Method}

\section{Design}

Study design is an experimental investigation of two groups, an experimental group (EG) to which an integrated cognitiveperceptual-cognitive program and a control group (CG) was applied standard curriculum. Evaluation was carried out during 8 months along 3 successive measures.

\section{Participants}

A total of 20 students with ASD, of age ranges between 6 and 14 years, distributed in both groups, have participated in this study. For the EG 10 students have been selected, of which, 4 students are between 6-8 years old, 3 between 9-11 years old and 3 between 12 
and 14 years old; in the GC another 10 students have participated, of which 3 have between 6-8 years, 3 between 7-9 years and 4 between 12-14 years.

\section{Variables}

Analysis has been configured based on following variables:

a) Variable "group": EG \& CG.

b) Variable "age": age ranges.

c) Variable "sensory": cognitive-perceptual integration (3 measures)

d) Variable "concept": categorial-conceptual coding (3 measures).

\section{Data analysis}

Analysis aims to perform a comparative study of related effects between the "sensory" variable and "concept" variable, in relation to "group" variable, as well as to determine if there're differences in this comparative study in relation to range old. Data analysis, the ANOVA test of a 1-factor repeated measures was carried out, 1 -factor being the arithmetic $\mu$ of data found in "sensory" and "concept" variables. Also, we proceeded to observe optional posthoc test of the repeated measures analysis of 1 -factor ANOVA.

\section{Instruments}

Instruments used have been following:

A. Reading analysis of a curricular text adapted to different competencies of students. If they don't have acquired reading' ability, it's been valued according the given answers to an adapted story to individual needs; and

B. Two scales use of evaluation measures, make ad hoc, according to standardized criterion indices for "sensory" and "concept" variables indicated in tables 1 (sensory variable) and 2 (concept variable) (Table 1 \& 2).

Table 1: Standardized criteria for "sensory" variable: cognitiveperceptual integration.

\begin{tabular}{|c|c|c|}
\hline Motivation & Criteria & p \\
\hline \multirow{4}{*}{ Motivation is not observed } & 4 \\
\cline { 2 - 3 } & External little motivation is acquired. & 3 \\
\cline { 2 - 3 } & There's motivation but induced. & 2 \\
\cline { 2 - 3 } & Intrinsic motivation is frequently shown. & 1 \\
\cline { 2 - 3 } & No disorder. & 0 \\
\hline
\end{tabular}

\begin{tabular}{|c|c|c|}
\hline Attention & Criteria & p \\
\hline \multirow{4}{*}{} & Very dispersed attention towards stimuli. & 4 \\
\cline { 2 - 3 } & $\begin{array}{c}\text { Temporary attention is focused, with external } \\
\text { help. }\end{array}$ & 3 \\
\cline { 2 - 3 } & Attention is made, but it's induced. & 2 \\
\cline { 2 - 3 } & Intrinsic attention is often developed. & 1 \\
\cline { 2 - 3 } & No disorder. & 0 \\
\hline
\end{tabular}

\begin{tabular}{|c|c|c|}
\hline Perception & Criteria & p \\
\hline \multirow{4}{*}{} & Concretism stimulate. & 4 \\
\cline { 2 - 3 } & Concrete partial meanings are perceived. & 3 \\
\cline { 2 - 3 } & There's meanings' perception, with help. & 2 \\
\cline { 2 - 3 } & Meanings are frequently integrated. & 1 \\
\cline { 2 - 3 } & Meanings are integrated. & 0 \\
\hline
\end{tabular}

\begin{tabular}{|l|c|c|}
\hline $\begin{array}{c}\text { Concept } \\
\text { coding }\end{array}$ & Criteria & p \\
\hline \multirow{4}{*}{} & Information is lost in work memory (WM). & 4 \\
\cline { 2 - 3 } & Little information is encoded, with help. & 3 \\
\cline { 2 - 3 } & Information is encoded, with help. & 2 \\
\cline { 2 - 3 } & Frequently meanings coding is carried out. & 1 \\
\cline { 2 - 3 } & Incoming information is encoded. & 0 \\
\hline
\end{tabular}

\begin{tabular}{|c|c|c|}
\hline Shemas & Criteria & p \\
\hline \multirow{4}{*}{} & Information schemas aren't elaborated. & 4 \\
\cline { 2 - 3 } & Few schemas are developed, with external help. & 3 \\
\cline { 2 - 3 } & Schemes are developed with help. & 2 \\
\cline { 2 - 3 } & Schemas are frequently made. & 1 \\
\cline { 2 - 3 } & Information schemes are developed. & 0 \\
\hline
\end{tabular}

\begin{tabular}{|c|c|c|}
\hline $\begin{array}{l}\text { Synthesis- } \\
\text { analysis }\end{array}$ & Criteria & $\mathbf{p}$ \\
\hline & There's no analysis and synthesis of information. & 4 \\
\hline & $\begin{array}{l}\text { Few analyzes and syntheses are developed, with } \\
\text { external help. }\end{array}$ & 3 \\
\hline & $\begin{array}{l}\text { Analysis and synthesis is developed with } \\
\text { external help. }\end{array}$ & 2 \\
\hline & $\begin{array}{l}\text { Analysis and synthesis are frequently carried } \\
\text { out. }\end{array}$ & 1 \\
\hline & $\begin{array}{c}\text { Analysis and synthesis of the information is } \\
\text { developed. }\end{array}$ & 0 \\
\hline
\end{tabular}

\begin{tabular}{|c|c|c|}
\hline $\begin{array}{c}\text { Categori } \\
\text { zation }\end{array}$ & Criteria & p \\
\hline & Conceptual categories aren't elaborated. & 4 \\
\hline & Conceptual category is elaborated with help. & 3 \\
\hline & $\begin{array}{c}\text { Conceptual categories are developed, with } \\
\text { external help. }\end{array}$ & 2 \\
\hline & Conceptual categories are frequently carried out. & 1 \\
\hline & Concept categories are developed. & 0 \\
\hline
\end{tabular}

\begin{tabular}{|c|c|c|}
\hline Hierarchy & Criteria & p \\
\hline & Main and secondary ideas aren't elaborated. & 4 \\
\hline & $\begin{array}{c}\text { It elaborates some main and secondary ideas, } \\
\text { with external help. }\end{array}$ & 3 \\
\hline & Information is hierarchized, with external help. & 2 \\
\hline & Information hierarchy is frequently carried out. & 1 \\
\hline & $\begin{array}{c}\text { Main and secondary ideas over the text are } \\
\text { elaborated. }\end{array}$ & 0 \\
\hline
\end{tabular}




\begin{tabular}{|c|c|c|}
\hline $\begin{array}{c}\text { Information } \\
\text { recovery }\end{array}$ & Criteria & p \\
\hline \multirow{4}{*}{} & Information is recovered in a very limited way. & 4 \\
\cline { 2 - 3 } & $\begin{array}{c}\text { Some information is recovered, with external } \\
\text { help. }\end{array}$ & 3 \\
\cline { 2 - 3 } & $\begin{array}{c}\text { Information is recovered, with help of external } \\
\text { keys. }\end{array}$ & 2 \\
\cline { 2 - 3 } & Coded information is recovered frequently. & 1 \\
\cline { 2 - 3 } & Coded information is recovered. & 0 \\
\hline
\end{tabular}

\begin{tabular}{|c|c|c|}
\hline $\begin{array}{c}\text { Relationhsips } \\
\text { between } \\
\text { information }\end{array}$ & Criteria & p \\
\hline \multirow{7}{*}{} & $\begin{array}{c}\text { No relationships are established between new } \\
\text { and previous information. }\end{array}$ & 4 \\
\cline { 2 - 3 } & Few relationships developed, with help. & 3 \\
\cline { 2 - 3 } & Relationships developed, with external help. & 2 \\
\cline { 2 - 3 } & $\begin{array}{c}\text { Relationships are frequently made between the } \\
\text { information, both proviniente from data and } \\
\text { cognitive system. }\end{array}$ & 1 \\
\cline { 2 - 3 } & $\begin{array}{c}\text { Relationships between conceptual contents are } \\
\text { developed. }\end{array}$ & 0 \\
\hline
\end{tabular}

Table 2: Standard criteria for variable "concept": conceptual coding.

\begin{tabular}{|l|c|c|}
\hline Undarstanding & Criteria & p \\
\hline & Understanding is very limited. & 4 \\
\hline & Enunciates are understood. & 3 \\
\hline & Concepts are understood, with help. & 2 \\
\hline & Concepts are frequently understood. & 1 \\
\hline & Conceptual stimuli are understood. & 0 \\
\hline
\end{tabular}

\begin{tabular}{|c|c|c|}
\hline $\begin{array}{c}\text { Conceptual } \\
\text { integration }\end{array}$ & Criteria & p \\
\hline \multirow{4}{*}{} & Concepts are not integrated. & 4 \\
\cline { 2 - 3 } & $\begin{array}{c}\text { Very limited concepts are integrated, with } \\
\text { help. }\end{array}$ & 3 \\
\cline { 2 - 3 } & Various concepts are integrated, with help. & 2 \\
\cline { 2 - 3 } & $\begin{array}{c}\text { Integrations of several concepts are } \\
\text { frequently carried out. }\end{array}$ & 1 \\
\cline { 2 - 3 } & $\begin{array}{c}\text { New concepts are integrated with the } \\
\text { information. }\end{array}$ & 0 \\
\hline
\end{tabular}

\begin{tabular}{|c|c|c|}
\hline $\begin{array}{c}\text { Categorial } \\
\text { relationships }\end{array}$ & Criteria & p \\
\hline \multirow{7}{*}{} & Conceptual categories are not formed. & 4 \\
\cline { 2 - 3 } & Some category is developed, with help. & 3 \\
\cline { 2 - 3 } & $\begin{array}{c}\text { They develop categories that group } \\
\text { different concepts, with external help. }\end{array}$ & 2 \\
\cline { 2 - 3 } & Categorial setting are frequently made. & 1 \\
\cline { 2 - 3 } & Categorial setting are developed. & 0 \\
\hline
\end{tabular}

\begin{tabular}{|c|c|c|}
\hline Functionality & Criteria & p \\
\hline & $\begin{array}{c}\text { Information is not applied to contextual } \\
\text { practice. }\end{array}$ & 4 \\
\hline & Limited concepts apply, with help. & 3 \\
\hline & Concepts are applied functionally, with help. & 2 \\
\hline & $\begin{array}{c}\text { Concepts learned to practice are frequently } \\
\text { applied. }\end{array}$ & 1 \\
\hline & $\begin{array}{c}\text { Concepts acquired are applied to functional } \\
\text { practice. }\end{array}$ & 0 \\
\hline
\end{tabular}

\section{Procedure}

"Sensory" and "concept" variables have been obtained in following way.

"Sensory" is result of means $(\mu)$ of 10 standardized criteria analyzed by professionals they intervene directly with students, valued with $0=$ no disorder to $4=$ severe deficit: 1 ) motivationbehavior, 2) attention, 3) stimuli perception, 4) coding, 5) scheme elaboration, 6) analysis and synthesis, 7) conceptualcategorization, 8) concepts hierarch, 9) information recovery, and 10) relationships-links with new information. "Concept" variable (conceptual integration) is made up of $\mu$ of criterial scores in 4 dimensions: 1) conceptual understanding, 2) conceptual integration, 3) relations-categories, and 4) conceptual functionality. The quantitative measures are: $0=$ there's no disorder and $8=$ severe deficit.

\section{Program}

Applied cognitive-perceptive integration program aims to set an integrated continuity of all lived situations, in order to generate the higher functionality and meaningfulness of learning, starting from the previously conceptual semantic units. In this way, academic aspects are integrated into behavioral and psychomotor elements, as well as daily organizational and structural aspects, through systematic and continuous evaluation of exchange of data in all intervention contexts.

Program consists of the following structure:

a. Previous analysis of the initiated behaviors: "Initiation".

b. The situational aspects' reconstruction.

c. Experiential methodological process based in the selfmanagement with help.

d. Analysis and synthesis of situation and its reconstruction (self-management).

e. Exchange of learned roles.

f. Establishment of empathy' situations in the reconstructed experiences.

g. The behavior expression.

h. Cognitive decoding of situation as a whole. 
i. Situation modification, through creation of alternative contexts (generalization).

j. Cognitive reconstruction considering the alternatives (self-management).

k. Learning assessment.

l. Personal Agenda: "end".

For example, following development of one programmatic session with Bruno (name is fictitious), of 12 old years, who is studying 1st of Compulsory Secondary Education, can be observed:

\section{i. Start}

Review of school intercommunication Agenda.

Indications: concept of multiple numbers is deficit, although he knows how to carry out related mathematical operations.

- Hi Alex! Teacher says, touching Bruno lightly on shoulder.

- Hi! Bruno answered.

- How about today in math class? -Well.

- Did teacher ask you? -Yes.

- Have you been able reply? -Good.

- What did he ask you? -Resolve the following problem: calculate the multiples of 17 between 800 and 900 .

- Did you answer? -Yes.

- Did he asked you something else? -Yes.

- What else did he ask? - Then he asked me to define the multiple numbers.

- What did you answer? -I didn't know how to say it (conceptual need detected).

- What did the teacher say? -Regular, that I should study more.

- Did not you like it? -No (emotional need detected).

\section{ii. Situation reconstruction}

Class question: Find multiples of 17 between 800 and 900:

$800 / 17=4848 * 17=816,49 * 17=833,50 * 17=850,51 * 17=867$, $52 * 17=884$

Multiple numbers are: 816, 833, 850, 867, 884.

-What have you make first? -I divided 800 by number 17 .

-Why did you do that? -To know where to start.

-Then, what did you do? -Multiply the result of 48 by 17 , increasing one by one until you scope 900 .

-What does 17 number represent in the problem? -The multiple that must be found.

-What does 48 number represent? -The number by which it multiplies 17.

-What you have done? -I multiplied requested number by all possible numbers (supervised self-management).

Agenda: "I multiplied requested number by all possible numbers. Concept: number multiple is multiply by number all possible natural numbers".

The process continues in family.

\section{iii. Interactive process: "Role Playing"}

Bruno becomes the teacher of a small group of classmates to whom he teaches concept of number multiples (self-management).

Number multiples of 4 .

$4 / 4=1$

$1 * 4=4,2 * 4=8,3 * 4=12,4 * 4=16$

Number multiples are: 8,12,16.

Concept: number multiples are the result of multiplying the number by all possible natural numbers.

For example:

-Bruno says to Alicia (figurative name): Do you calculate multiples of 5 ?

$1 * 5=5,2 * 5=10,3 * 5=15$

$(10,15)$.

-Very well (says Bruno).

-Now, calculate multiples of 6? -I don't remember.

- Very bad (says Bruno).

\section{iv. Analysis and interpretation}

Communication between the teacher and Bruno regarding following situation.

- Do you already know how to define the multiple number? -Yes.

- How have you felt as a teacher? -Fine.

- You said to Alicia: very badly, why? -Because she didn't know how to calculate the multiples.

- Why did you say "very bad"? -For her to learn.

- Therefore, was your intention good or bad? -Good.

- How do you think Alicia felt when you said "very badly"? -Wrong.

- This morning, how did you feel when you told teacher: 
"regular"? -Wrong.

- Do you think teacher did with good or bad intentions? -Good (emotional semantic category).

\section{v. Roles exchange}

According to teacher's instructions, Bruno tells Alicia to develop an activity and, then, assess it, finally roles are exchanged (their actions previously learned).

Bruno: You must walk and count with drum sound, when I stop playing, you also have to stop, have you understood) - Yes (Alicia)).

$-\quad-1-2-3 \ldots$

-Stop (She took a while to stop...) -Ok, I'm sorry.

-You've done it wrong.

Now Alicia is Bruno's teacher:

Alicia: You must walk and count numerically with drum sound, when I stop playing, you have to stop - Ok (Bruno).

$--1-2-3$.

Very well! (says Alicia).

\section{vi. Empathy development}

The teacher asks Bruno:

- What do you think Alicia felt when you said "bad"? -I don t know.

- Express your possible feeling with finger paint (choose the color). You paint freely (priority of this concept is marked with red color).

Now, Alicia asks Bruno:

-What have you felt when I said "wrong"? -Very angry.

\section{vii. Expression}

Each partner chooses a finger paint colour and paints freely over the cardboard.

- $\quad$ Teacher asks the two classmates:

- To Bruno: - Why did you choose green colour?

- - "Because I had a good time and I like the colour".

- $\quad$ To Alicia: - Why did you choose colour black?

- - - "Because I didn't like him saying" bad".

\section{viii. Cognitive analysis}

Teacher asks Bruno:

-In your activity assessment, could you have said a different phrase to Alicia? -Don't.
-Why? -Because she did it wrong.

-During the exercise: Did she move with the sound rhythm? -Yes.

-Then, did that part do it right? -Yes.

-When the drum stopped, she didn't stop? -Don't.

-Therefore, did that part did it wrong? -Yes.

- So, could you have told her that did first part of exercise very well and another part wrong? -Yes.

-Do you think she would have felt better? -Yes.

-If teacher told you that you did the multiples exercise very well, but you only did the definition wrong, would you have felt better? -Yes.

-How many parties did the activities? -Two (self-management).

\section{ix. Modification situational}

Bruno suggest to Slice an action and then values it:

- Do you have to give as many touches with xylophone as they are multiples of 2? You have understood?

(Figure 1)

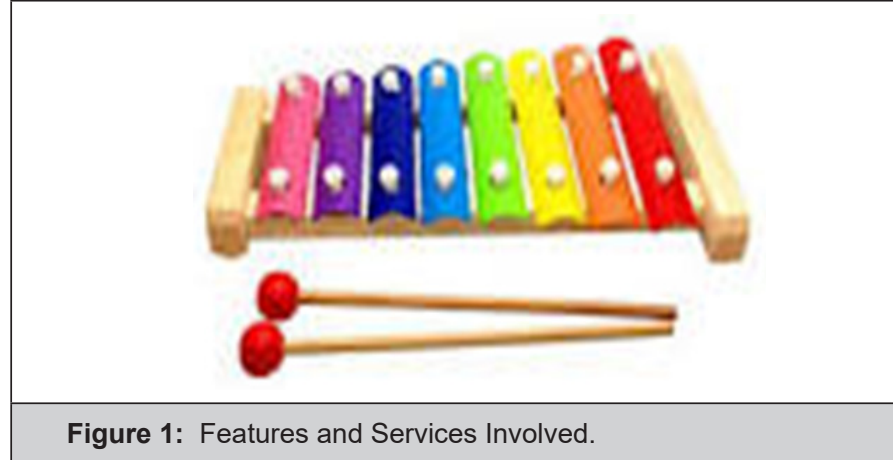

-Yes.

-Multiple of 2?

-Now, multiple of 19 , which is between number 100 and 150 ? -I don't know.

Evaluation: You have done well the first part of exercise and bad the second one (generalization).

\section{x. Cognitive reconstruction}

Teacher asks Bruno questions:

- Have you understood concept of multiple number? Can you define it? -I's result of multiplying that number by all possible numbers. -Very well.

- Have you understood the teacher attitude when she has upbraided you? -Yes, but, teacher didn't tell me I did well the other party 
- It's true.

Therefore, can behaviors have several parts? Yes.

Finally, Bruno makes the following inputs in your AGENDA: "Multiple number is result of multiplying all the possible numbers by the number" (for transfer to school and family).

\section{xi. Evaluation}

In this section, a systematic evaluation of learned process is carried out, in order to assurance the planned aims have been correctly acquired through of ad hoc built scale (Table 3).

\begin{tabular}{|c|c|c|}
\hline \multicolumn{2}{|l|}{ Table 3: Ad hoc systematic evaluation. } \\
\hline Date & Item & $\begin{array}{c}\text { Acquired } \\
\text { (0-5) }\end{array}$ \\
\hline $\mathrm{xxx}$ & Definition of the multiple number meaning. & 5 \\
\hline $\mathrm{xxx}$ & $\begin{array}{c}\text { Understanding of the interactive social- } \\
\text { emotional situations. }\end{array}$ & 3 \\
\hline $\mathrm{xxx}$ & Facing with emotional situation. & 2 \\
\hline
\end{tabular}

xii. Final: Agenda.

Results

\begin{tabular}{|c|c|c|c|c|c|c|c|}
\hline \multirow{2}{*}{$\begin{array}{c}\text { Within Subjects } \\
\text { Effect }\end{array}$} & \multirow[b]{2}{*}{ Mauchly's W } & \multirow{2}{*}{$\begin{array}{l}\text { ApproxChi- } \\
\text { Square }\end{array}$} & \multirow[b]{2}{*}{ df } & \multirow[b]{2}{*}{ Sig. } & \multicolumn{3}{|c|}{ Epsilon(a) } \\
\hline & & & & & Huynh-Feldt & Lower-bound & $\begin{array}{l}\text { Greenhouse- } \\
\text { Geisser }\end{array}$ \\
\hline factor1 & 0.32 & 13.69 & 14 & 0.48 & 0.73 & 1 & 0.2 \\
\hline \multicolumn{8}{|c|}{$\begin{array}{l}\text { Tests the null hypothesis that the error covariance matrix of the orthonormalized transformed dependent. Variables are proportional to an identity } \\
\text { matrix. } \\
\text { a. May be used to adjust the degrees of freedom for the averaged tests of significance. Corrected tests are displayed in the Tests of Within-Subjects Effects } \\
\text { table. }\end{array}$} \\
\hline
\end{tabular}

Statistical mean of measured criteria mentioned for perceptivecognitive variables have conformed "sensory" and "concept" variables respectively. Both variables constitute factor1 of the analysis, in order to analyze the set of variances and co- variances between themselves and with respect to "group" variable. To analyze these effects, it proceeded with the ANOVA W test of Mauchly (Table 4). Tests the null hypothesis that the error covariance matrix of the orthonormalized transformed dependent. Variables are proportional to an identity matrix.

a. May be used to adjust the degrees of freedom for the averaged tests of significance. Corrected tests are displayed in the Tests of Within-Subjects Effects table.

b. Design: Intercept+ group + age+ group* age.

Within Subjects Design: factor1.

As observed W statistical analysis rejects sphericity hypothesis $=.32(\mathrm{sig}=.48)$, therefore data related to the univariate ANOVA $\mathrm{F}$ of the repeated measures intra- subject test are carried out below since it constitutes an index correction for small samples more stable (Table 5).

\begin{tabular}{|c|c|c|c|c|c|c|}
\hline \multicolumn{2}{|c|}{ Source } & Type III Sum of Squares & df & Mean Square & $\mathbf{F}$ & Sig. \\
\hline \multirow{4}{*}{ factor 1} & Sphericity Assumed & 35.63 & 5 & 7.12 & 54 & 0 \\
\hline & Greenhouse-Geisser & 35.63 & 0.66 & 9.72 & 54 & 0 \\
\hline & Huynh-Feldt & 35.63 & 5 & 7.12 & 54 & 0 \\
\hline & Lower-bound & 35.63 & 1 & 35.63 & 54 & 0 \\
\hline \multirow{4}{*}{ factor1* group } & Sphericity Assumed & 7.28 & 5 & 1.45 & 11 & 0 \\
\hline & Greenhouse-Geisser & 7.28 & 3.66 & 1.98 & 11 & 0 \\
\hline & Huynh-Feldt & 7.28 & 5 & 1.45 & 11 & 0 \\
\hline & Lower-bound & 7.28 & 1 & 7.28 & 11 & 0 \\
\hline \multirow{4}{*}{ factor $1^{*}$ age } & Sphericity Assumed & 2.87 & 10 & 0.28 & 2.2 & 0.03 \\
\hline & Greenhouse-Geisser & 2.87 & 7.33 & 0.39 & 2.2 & 0.05 \\
\hline & Huynh-Feldt & 2.87 & 10 & 0.28 & 2.2 & 0.03 \\
\hline & Lower-bound & 2.87 & 2 & 1.43 & 2.2 & 0.15 \\
\hline
\end{tabular}




\begin{tabular}{|c|c|c|c|c|c|c|}
\hline \multirow{4}{*}{$\begin{array}{c}\text { factor1 * group } \\
* \text { age }\end{array}$} & Sphericity Assumed & 0.77 & 10 & 0.07 & 0.6 & 0.82 \\
\cline { 2 - 7 } & Greenhouse-Geisser & 0.77 & 7.33 & 0.1 & 58 & 0.77 \\
\cline { 2 - 7 } & Huynh-Feldt & 0.77 & 10 & 0.07 & 58 & 0.82 \\
\cline { 2 - 7 } & Lower-bound & 0.77 & 70 & 0.38 & 0.13 & 0 \\
\cline { 2 - 7 } Error(factor1) & Sphericity Assumed & 9.29 & 51.3 & 0.18 & 0 & 0 \\
\cline { 2 - 7 } & Greenhouse-Geisser & 9.29 & 70 & 0.13 & 0 & 0 \\
\cline { 2 - 7 } & Huynh-Feldt & 9.29 & 14 & 0.66 & 0 & 0 \\
\hline
\end{tabular}

Significance critical levels indicate that there's a positive influence between both variables: "sensory" and "concept": factor 1, whose most significant data are: Sphericity Assumed: sig $=.00$ and Greenhouse-Geisser: sig = .00.

Likewise, influence of this factor1 in relation to variable "group" shows that there're significant differences in variance exerted by factor1 according to group type (factor1* group), whose data are: Sphericity Assumed: sig $=.00$ and GreenhouseGeisser: sig $=.00$, which allows to conclude the program has found important differences between the EG and the GC, with significant improvements being observed along the 3 successive measures in participants that make up EG (Table 6).

\begin{tabular}{|c|c|c|c|c|c|}
\hline \multicolumn{2}{|c|}{ Group } & \multirow{2}{*}{$\frac{\mathbf{N}}{10}$} & \multirow{2}{*}{$\begin{array}{c}\text { Mean } \\
0.5\end{array}$} & \multirow{2}{*}{$\begin{array}{c}\text { Std. Deviation } \\
0.52\end{array}$} & \multirow{2}{*}{$\begin{array}{c}\text { Std. Error Mean } \\
0.16\end{array}$} \\
\hline cencory 1 & experimental & & & & \\
\hline Sentisoty & control & 10 & 0.6 & 0.51 & 0.16 \\
\hline \multirow{2}{*}{ sensory2 } & experimental & 10 & 1.3 & 0.67 & 0.21 \\
\hline & control & 10 & 1 & 0.66 & 0.21 \\
\hline \multirow{2}{*}{ sensory3 } & experimental & 10 & 2.4 & 0.51 & 0.16 \\
\hline & control & 10 & 1.4 & 0.51 & 0.16 \\
\hline \multirow{2}{*}{ concept1 } & experimental & 10 & 1 & 0. (a) & 0 \\
\hline & control & 10 & 1 & $0 .(\mathrm{a})$ & 0 \\
\hline \multirow{2}{*}{ concept2 } & experimental & 10 & 2.2 & 0.42 & 0.13 \\
\hline & control & 10 & 1.6 & 0.51 & 0.16 \\
\hline \multirow{2}{*}{ concept3 } & experimental & 10 & 2.6 & 0.51 & 0.16 \\
\hline & control & 10 & 1.4 & 0.51 & 0.16 \\
\hline
\end{tabular}

However, variances interaction between variables that make up factor1 and "age" variable show significant partial differences between participants age ranges. In this sense, post-hoc statistical test indicates that there're differences between the 6-8 years' age range with 9-11 years' age range $($ sig $=.03)$ and with $12-14$ years' interval ( $\operatorname{sig}=.00)$, but there're no differences between 9-11 years range and interval between 12 and 14 age years (sig = .81) (Table 7).

\begin{tabular}{|c|c|c|c|c|c|c|}
\hline \multirow{2}{*}{ (I) Age } & \multirow{2}{*}{ (J) Age } & \multirow{2}{*}{$\begin{array}{c}\text { Mean Difference } \\
(I-J)\end{array}$} & \multirow{2}{*}{ Std. Error } & \multirow{2}{*}{ Sig. } & \multicolumn{2}{|c|}{ 95\% Confidence Interval } \\
\hline & & & & & Upper Bound & Lower Bound \\
\hline \multirow{2}{*}{ 6-8 years } & 9-11 years & $-.40(*)$ & 0.14 & 0.03 & -0.79 & -0.02 \\
\hline & 12-14 years & $-.50(*)$ & 0.14 & 0 & -0.87 & -0.12 \\
\hline \multirow{2}{*}{ 9-11 years } & $6-8$ years & $40\left(^{*}\right)$ & 0.14 & 0.03 & 0.02 & 0.79 \\
\hline & 12-14 years & -0.09 & 0.14 & 0.81 & -0.47 & 0.29 \\
\hline \multirow{2}{*}{$12-14$ years } & $6-8$ years & $50\left(^{*}\right)$ & 0.14 & 0 & 0.12 & 0.87 \\
\hline & 9-11 years & 0.09 & 0.14 & 0.81 & -0.29 & 0.47 \\
\hline
\end{tabular}

For graphical observation of this results, graphs corresponding distributed according to age range (Graphs 1-3).

to differences found between both groups can be observed, 


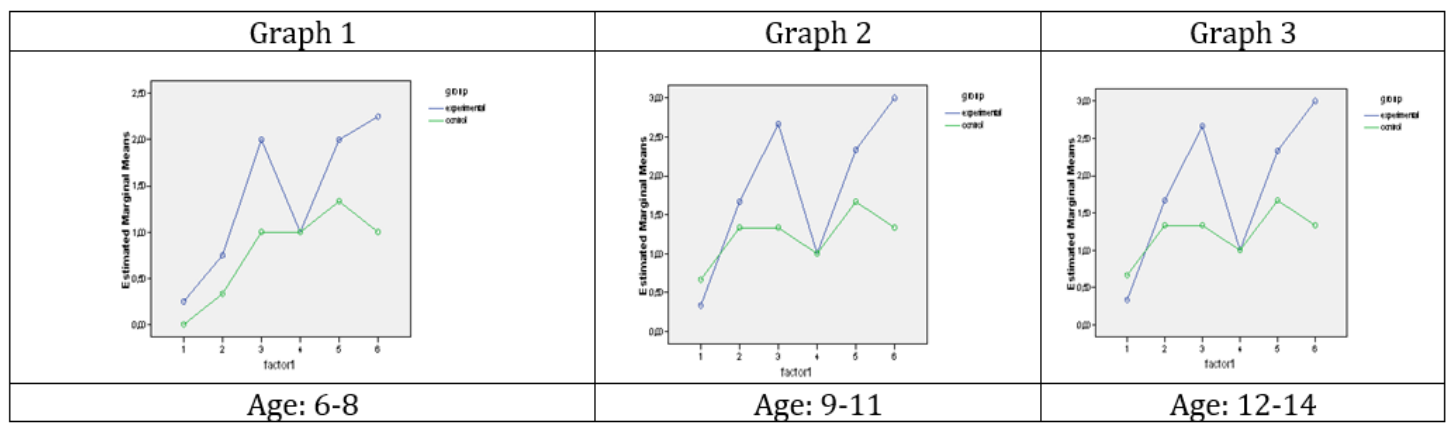

Graph 1-3: Baseline factor1 evolution between the CG and CG, by age intervals.

\section{Discussion}

Children with ASD, who were trained according to program strategies, based on school, improved significantly more in relation to CG pairs. But, next to criteria evaluated, it highlighted those aspects related to self-management when they were readied in a previous process, which allows to adjust the proposals learned to new situations that may be similar. Therefore, learning would probably not have been successful, if they weren't followed by functional environments, highly significant for the students, both in relation to family environment and to education inclusive ambit, which encourages participation of all factors, with an applied methodology, based on a highly functional, meaningful, coherent and natural environment, with last aim of facilitating learning self-management, as well as his independence and autonomy for development (Figure 2).

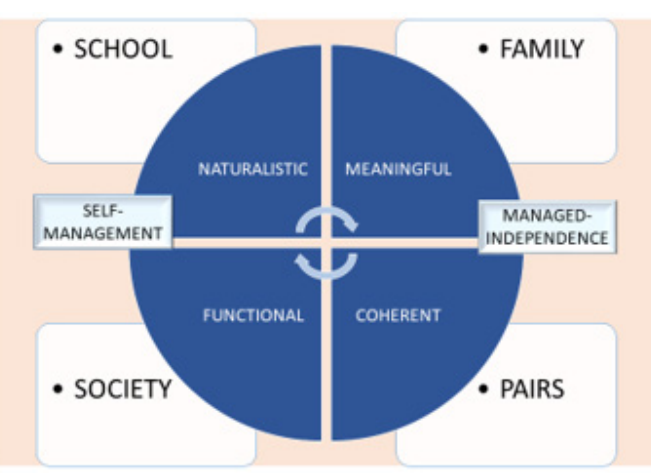

Figure 2: Source: self-elaboration.

This methodology is effective when it's applied, then, in contexts of general or regular education. Studies of Include in References [16] developed through practices based on shared reading and integrated instruction, implemented in context of an English class, prove that learning in these contexts improves access to people curriculum with specific educational support needs. Indeed, Strain [17] presents a conclusive research work, which constitutes a 4-year follow-up study of a randomized trial of learning experiences for pre-school children with ASD and their families in schools "Learning Experiences and Alternative Program (LEAP)" and concludes that, generally, significant differences are observed among groups analyzed, both in cognitive development, as in social skills, and when measures refer to global aspects, differences affected all the measures in favor of students with ASD registered in inclusive settings.

Likewise, participation of all factors involved, especially the family environment, is a fundamental variable that provides coherence to learning process implemented. Andersen, Bottcher \& Danmeyer [18] show that, precisely, the reason for use of learning at home is to facilitate functionality and coherence of programs, which allows to child progress in knowledge increasingly complex. Equally, study doesn't rule out need to adapt social practices outside the family, encouraging society support, both to allow the child development and to enhance family formation itself, in order to achieve decisive quotas of real inclusion policies.

Finally, it's important to highlight that all these processes can be widely favored by new technologies use in education adjusted to people with ASD. Peterson [19] offers a very significant study on adapted technologies during educational processes, which, according author, are underutilized in people with ASD, which may be depriving them of using important tools to reach their potential. Similarly, Simonson [20], in Las Vegas' Convention Acts, along the 15 articles of volume 2 , reflects the importance of new technologies to support development of programs applied to people with ASD, indicating the most appropriate teaching strategies to facilitate their cognitive development.

\section{Study Limitations}

This study presents the limitations of research analysis with groups with educational specific needs they're always small groups. Also, it's suitable to carry out longer duration tests to verify the data reflected in this research.

\section{Acknowledgement}

We want to thank the families, social, educational and psychiatric services of the Association of Families, Professionals and Researchers of People with ASD of Ourense (Spain), as well as families and those educational centers participating in the study.

\section{References}

1. Ellis S, Habib E, Edwards J, Saffran J, Venker CE (2016) Lexical Processing in Toddlers with ASD: Does Weak Central Coherence Play a Role? Journal of Autism and Developmental Disorders 46(12): 3755-3769. 
2. Ojea M (2018) Comparative Analysis of Development Program of Concepts and Categories through Cognitive Perceptive Networks in Students with Autism Spectrum Disorder. Scholarly Journal of Psychology and Behavioral Sicences 1(3): 1-6.

3. Coderre EL, Chernenok M, Gordon B, Ledoux K (2017) Linguistic and Non-Linguistic Semantic Processing in Individuals with Autism Spectrum Disorders: An ERP Study. Journal of Autism and Developmental Disorders 47(3): 795-812.

4. Luxford S, Hadwin JA, Kovshoff H (2017) Evaluating the Effectiveness of a School-Based Cognitive Behavioural Therapy Intervention for Anxiety in Adolescents Diagnosed with Autism Spectrum Disorder. Journal of Autism and Developmental Disorders 47(12): 3896-3908.

5. Mussey J, Dawkins, T (2017) Cognitive Behavioral Intervention (CBI)EBP Brief Packet. National Professional Development Center on Autism Spectrum Disorders. University of North Carolina, Publications Office FPG Child Development Institute.

6. Moskowitz LJ, Walsh CE, Mulder E, McLaughlin D, Magito H Greg, et al. (2017) Intervention for Anxiety and Problem Behavior in Children with Autism Spectrum Disorder and Intellectual Disability. Journal of Autism and Developmental Disorders 47(12): 3930-3948.

7. Clarke Ch, Hill V, Charman T (2017) School Based Cognitive Behavioral Therapy Targeting Anxiety in Children with Autistic Spectrum Disorder: A Quasi-Experimental Randomised Controlled Trail Incorporating a Mixed Methods Approach. Journal of Autism and Developmental Disorders 47(12): 3883-3895.

8. Drmic IE, Aljunied M, Reaven J (2017) Feasibility, Acceptability and Preliminary Treatment Outcomes in a School-Based CBT Intervention Program for Adolescents with ASD and Anxiety in Singapore. Journal of Autism and Developmental Disorders 47(12): 3909-3929.

9. Pan Ch, Chu Ch, Tsai Ch, Sung M, Huang Ch, et al. (2017) The Impacts of Physical Activity Intervention on Physical and Cognitive Outcomes in Children with Autism Spectrum Disorder. Autism: The International Journal of Research and Practice 2(2): 190-202.

10. Ketcheson L, Hauck J, Ulrich D (2017) The Effects of an Early Motor Skill Intervention on Motor Skills, Levels of Physical Activity, and Socialization in Young Children with Autism Spectrum Disorder: A Pilot Study. Autism: The International Journal of Research and Practice 21(4): 481-492.
11. Tal-Atzili O, Salls J (2017) Qigong Sensory Training Pilot Study: A Tactile Home Program for Children with or At-Risk for Autism. Journal of Occupational Therapy, Schools \& Early Intervention 10(4): 366-388.

12. Nelson C, Paul K, Johnston SS, Kidder JE (2017) Use of a Creative Dance Intervention Package to Increase Social Engagement and Play Complexity of Young Children with Autism Spectrum Disorder. Education and Training in Autism and Developmental Disabilities 52(2): 170-185.

13. Lyons GL (2017) Cumulative Evidence and Consensus of Pivotal Response Treatment as a Naturalistic Developmental Behavior Intervention for Young Children with Autism. University of Wisconsin: ProQuest LLC.

14. Koegel RL, Koegel LK (2006) Pivotal Response Treatments for Autism: Communication, Social, and Academic Development. Baltimore: Brookes Pub. Co.

15. Koegel RL, Koegel LK (2012) The PRT Pocket Guide: Pivotal Response Treatment for Autism Spectrum Disorders. Baltimore: Brookes Pub. Co.

16. Ruppar AL, Afacan K, Yang YL, Pickett KJ (2017) Embedded Shared Reading to Increase Literacy in an Inclusive English/ Language Arts: Preliminary Efficacy and Ecological Validity. Education and Training in Autism and Developmental Disabilities 52(1): 51-63.

17. Strain PS (2017) Four-Year Follow-Up of Children in the LEAP Randomized Trial: Some Planned and Accidental Findings. Topics in Early Childhood Special Education 37(2): 121-126.

18. Andersen ER, Bottcher L, Dammeyer J (2017) An Interview Study of Why Parents Conduct Intensive ABA Home Training for Their Child with Autism Spectrum Disorder. An Analysis from the Lens of the Dialectical Disability Model. European Journal of Special Needs Education 32(2): 270-286.

19. Peterson DH (2017) Parental and Teacher Perspectives on Assistive Technology. Dissertation, University of Minnesota: ProQuest LLC.

20.Simonson M (Ed.) (2016) Annual Proceedings of Selected Papers on the Practice of Educational Communications and Technology Presented at the Annual Convention of the Association for Educational Communications and Technology. Bloomington: Association for Educational Communications and Technology. 